the current smoker group maintained a 28 day quit and 4/13 (31\%) reduced tobacco intake. Psychological barriers to quitting were identified including smoking as a means of emotion regulation.

Conclusions For COPD smokers with a heavy smoking history and multiple quit attempts, and complex needs, additional psychological intervention alongside traditional quit smoking support may aid in preventing relapse, although further research is needed. For current smokers, the hypothesis was not supported, although the study did illuminate common themes regarding obstacles to quitting for this complex group who present a challenge to traditional quit smoking services.

It is clear that the current 'one size fits all' approach to smoking cessation does not meet the needs of these smokers who require more focused specific interventions to support smoking cessation including:

- Pre-quit support

- 'Cut down to quit' approach

- Long-term, intensive follow up

- Assertive outreach

- Multi-agency working

The above recommendations may provide a starting point for future service design.

\begin{tabular}{ll} 
Abstract P286 Table 1 & Patient demographics and morbidity \\
\hline Age (mean years \pm SD) & $59 \pm 10(n=57)$ \\
M:F & $27: 32$ \\
FEV1 (mean litres $\pm S D)$ & $1.59 \pm 0.8(n=37)$ \\
MRC Dyspnoea Score (mean $\pm S D)$ & $2.28 \pm 1(n=37)$ \\
Coexisting physical health problem e.g. arthritis, diabetes & $79 \%(n=29)$ \\
Coexisting mental health problem e.g. depression, anxiety & $64 \%(n=28)$ \\
\% with at least one psychosocial issue e.g. housing problems & $67 \%(n=30)$ \\
Unemployed & $57 \%(n=35)$ \\
Pack Year History (mean $\pm S D)$ & $41 \pm 22$ \\
No. of previous quit attempts & $3 \pm 2$ \\
\hline
\end{tabular}

\section{P287 MEASURING THE ACUTE CARDIOVASCULAR EFFECTS OF SHISHA SMOKING: A CROSS-SECTIONAL STUDY}

MK Kadhum, AEJ Jaffery, AH Haq, JB Bacon, BM Madden. St. George's University of London, London, UK

\subsection{6/thoraxjnl-2014-206260.405}

Objectives To investigate the acute cardiovascular effects of smoking shisha.

Design A cross-sectional study was carried out in six shisha cafes. Participants smoked shisha for a period between $45 \mathrm{~min}$ (minimum) and 90 min (maximum). The same brand of tobacco and coal was used.

Setting London, UK.

Participants

Participants were those who had ordered a shisha to smoke and consented to have their blood pressure, heart rate and carbon monoxide levels measured. Excluded subjects were those who had smoked shisha in the previous $24 \mathrm{~h}$, who smoke cigarettes or who suffered from cardiorespiratory problems.

Main outcome measures Blood pressure was measured using a sphygmomanometer. Pulse was measured by palpation of the radial artery. Carbon monoxide levels were obtained via a carbon monoxide monitor. These indices were measured before the participants began to smoke shisha and after they finished or when the maximum 90 min time period was reached.

Results Mean arterial blood pressure increased from $96 \mathrm{mmHg}$ to $108 \mathrm{mmHg}(\mathrm{p}<0.001)$. Heart rate increased from 77 and 91 bpm $(\mathrm{p}<0.001)$. Carbon monoxide increased from an average of 3 to $35 \mathrm{ppm}(\mathrm{p}<0.001)$. A correlation analysis showed no relationship between carbon monoxide and the other indices measured.

Conclusion The acute heart rate, blood pressure and carbon monoxide levels were seen to rise significantly after smoking shisha. The weak correlation between carbon monoxide levels and the other variables suggests that carbon monoxide levels had not contributed to their significant increase.

\section{P288 THE DESENSITISATION EFFECT OF GRAPHIC HEALTH WARNING LABELS AND CROSS-CULTURAL DIFFERENCES IN THE AWARENESS OF SMOKING RELATED CONSEQUENCES: COMPARING A LONDON AND SINGAPORE COHORT}

${ }^{1} \mathrm{C}$ Ratneswaran, ${ }^{2} \mathrm{~B}$ Chisnall, ${ }^{3} \mathrm{~A}$ Douiri, ${ }^{4} \mathrm{MY} \mathrm{Li},{ }^{4} \mathrm{~S}$ Tan, ${ }^{4} \mathrm{~S}$ Tan, ${ }^{4} \mathrm{C}$ Chang, ${ }^{5} \mathrm{D}$ Anantham, ${ }^{1} \mathrm{~J}$ Steier. 'Guy's and St Thomas' NHS Foundation Trust, London, UK; 'King's College London School of Medicine, London, UK; ${ }^{3}$ Department of Public Health Sciences, King's College London andNIHR Biomedical Research Centre, London, UK; ${ }^{4}$ National University of Singapore, Singapore; ${ }^{5}$ Singapore General Hospital, Singapore

\subsection{6/thoraxjnl-2014-206260.406}

Introduction and objectives Graphic Health Warning Labels (GHWL) assist in primary and secondary smoking prevention. A lack of evidence exists regarding their desensitisation with increased exposure. Investigating knowledge and attitudes around GHWL may allow better implementation of future public health policies. Singapore introduced GHWL in 2004, five years before they were introduced in the UK; this study aims to investigate any potential desensitisation effect by direct comparison.

Methods Data were collected from 266 smokers and non-smokers, 163 from London $(54.6 \%$ smokers, $54.0 \%$ male, mean age $52.4(17.8)$ ) and 103 from Singapore (47.6\% smokers, $77.7 \%$ male, mean age 57.7 (14.5)) between 2011 and 2013. A structured interview with fifty items, showing ten different GHWL, recorded demographics, smoking history, plans to quit and knowledge about the health-related consequences of smoking, as well as the emotional response, processing and impact of GHWL on behaviour. Participants further ranked hypothetical conditions that they could develop in terms of prevention and treatment.

Results The London cohort experienced significantly higher levels of 'disgust' when viewing GHWL than their Singapore counterparts (smokers $74.1 \%$ vs $49.0 \%, p=0.003$; non-smokers $83.8 \%$ vs $57.4 \%, \mathrm{p}<0.001)$, and felt GHWLs were a sufficient deterrent (smokers $33.7 \%$ vs $16.3 \%, p=0.029$; non-smokers $71.6 \%$ vs $50.0 \%, \mathrm{p}=0.013$ ). London non-smokers had a higher awareness of heart disease $(82.4 \%$ vs $32.0 \%, \mathrm{p}=0.007)$, stroke $(72.3 \%$ vs $28.2 \%, p=0.02)$, mouth and throat cancer $(95.6 \%$ vs $35.0 \%, \mathrm{p}<0.001)$ and lung cancer $(98.7 \%$ vs $35.0 \%$, p < 0.001 ) as smoking-related diseases. London smokers reported an increased motivation to quit if they hypothetically developed smoking-related disease $(85.2 \%$ vs $72.7 \%, \mathrm{p}=0.001)$. Blindness was the least well-known consequence overall (27.8\%), despite provoking the highest levels of fear amongst Singaporeans.

Conclusion A desensitisation effect of GHWL is observed in cohorts with an increased length of exposure, both in smokers 
and non-smokers. The socio-cultural background needs to be considered when running public health campaigns due to differences in perception and responses to GHWL. Investigating the awareness of risks such as blindness, that have a low knowledge score but a high deterring impact, provides the chance to create a tailored approach when addressing this desensitisation.

\section{P289 CARBOXYHAEMOGLOBIN LEVELS IN EMERGENCY DEPARTMENT PATIENTS: AN IMPORTANT TOOL IN VALIDATING SMOKING HISTORY AND DETECTING "MISSED SMOKERS"}

RW Fowler. Queen's Hospital, Romford, UK

\subsection{6/thoraxjnl-2014-206260.407}

Introduction Blood gas analysers in emergency departments (ED) routinely report carboxyhaemoglobin $(\mathrm{COHb})$ levels, but unless environmental carbon monoxide poisoning is suspected, measurements are ignored, particularly when blood gases have been performed to check acid-base status. Raised initial $\mathrm{COHb}$ levels are likely to indicate highly nicotine dependent smokers needing specialist support to quit.

Methods Data were obtained from 824 samples analysed in the ED in June 2013. There were 82 samples with $\mathrm{COHb}$ levels $>2.0 \%$, including 66 from 55 identifiable patients. Only the first measurements were used. Records were requested and checked for diagnosis and smoking history.

Results 42 records were retrieved. The highest initial $\mathrm{COHb}$ level was $13.5 \%$; 15 had levels $>4.5 \%$. There were eight confirmed COPD and two possible cases. Eleven patients presented with drug and alcohol poisoning. Table 1 lists diagnoses.

28/42 (66.7\%) were current tobacco smokers; in 14 (33.3\%) pack-years could be estimated. There was no smoking history recorded in seven patients. Seven others were recorded as nonsmokers, but in five there was evidence to contradict this. One had an explanatory blood disorder, leaving one unexplained high level. Four patients smoked cannabis; all smoked tobacco cigarettes as well.

Only 4/42 (10\%) were referred to stop smoking services (SSS), though 10/42 (23.8\%) were already known and one was referred subsequently. Two previous quitters had evidently relapsed. Of the remainder known to SSS, two self-referrers quit, three failed and eight missed appointments.

\begin{tabular}{|c|c|c|c|c|}
\hline \multirow{2}{*}{$\begin{array}{l}\text { Abstract P289 Tabl } \\
\text { diagnosis }\end{array}$} & \multicolumn{4}{|c|}{ Carboxyhaemoglobin (\%) } \\
\hline & Total & $2-2.5 \%$ & $2.5-4.5 \%$ & $>4.5 \%$ \\
\hline COPD & 8 & 1 & 1 & 6 \\
\hline Cardiac & 5 & 1 & 3 & 1 \\
\hline Drug/alcohol poisoning & 11 & 2 & 4 & 5 \\
\hline Sepsis & 3 & 1 & 1 & 1 \\
\hline Acute abdomen & 3 & 1 & 2 & 0 \\
\hline Haemoptysis ? lung cancer & 2 & 0 & 1 & 1 \\
\hline Diabetic & 2 & 1 & 1 & 0 \\
\hline Others & 8 & 2 & 5 & 1 \\
\hline Total & 42 & 9 & 18 & 15 \\
\hline
\end{tabular}

In the largest group, those with drug or alcohol poisoning, smoking history was of poorer quality - pack-years could only be estimated in one case. Most had underlying mental health problems. None were referred to SSS.

Conclusions 1. Patients with $\mathrm{COHb}$ levels $>2.0 \%$ are usually tobacco smokers.

2. Multiple substance dependence is common. Most have mental health problems and are rarely referred to SSS - a missed opportunity to improve life expectancy in this vulnerable population.

3. Carboxyhaemoglobin levels must be included in a systematic approach to identify people needing intensive support to quit smoking.

\section{Screening and treating sleep apnoea}

\section{P290 VALIDATION OF PREOPERATIVE SCREENING ALGORITHM FOR OBSTRUCTIVE SLEEP APNOEA}

VM Macavei, J Mitic, M Berger, OE Mohr, TC O'Shaughnessy. Newham University Hospital, Barts Health NHS Trust, London, UK

\subsection{6/thoraxjnl-2014-206260.408}

Background Obstructive sleep apnoea (OSA) has been previously reported as a major risk factor for perioperative adverse events. ${ }^{1}$ Identifying patients with undiagnosed OSA can potentially have an impact on co morbidities and hospitalisation costs. $^{2}$

Aim To validate a previously reported screening tool for surgical patients suspected of having OSA.

Method A prospective study was performed in a university hospital between 1st Dec 2013 and 1st June 2014. An easy to use screening tool (STOP BANG) has been addressed to all patients prior to overnight oximetry sleep study during chest clinic assessment. The STOP BANG questionnaire incorporated 8 questions related to Snoring, Tiredness, Observed apnoeas, high blood Pressure, BMI $>30 \mathrm{~kg} / \mathrm{m}^{2}$, Age $>50$, Neck size $>15$ " and male Gender. Each affirmative answer was marked with 1 point. OSA was defined as dip rate $\geq 10$ events per hour associated with an oxygen desaturation $\geq 4 \%$ below baseline value.

Results A total of 102 patients have been included, 57 males $(55.8 \%)$ and average age $50.8 \pm 14$ years. 52 patients $(50.9 \%)$ have been diagnosed with OSA out of which 29 patients (28.4\%) had severe OSA (defined as dip rate $\geq 30$ events per hour).

Using logistic regression analysis, a STOP BANG score of $\geq 3$ had a sensitivity of $94.2 \%$ and specificity $72 \%$ with a positive predictive value of $77.8 \%$ and a negative predictive value of 92.3\% in detecting OSA patients.

Conclusion We have identified a high incidence of OSA of $50.9 \%$ in our sleep study population. We have validated STOP BANG questionnaire to be a useful predictor of OSA with a sensitivity of $94.2 \%$ and specificity of $72 \%$. This can be used during pre anaesthetic assessment indicating the requirement of chest clinic referral for sleep study at a score of $\geq 3$.

\section{REFERENCES}

1 Kaw, R, Chung, F, Pasupuleti, et al. Meta-analysis of the association between obstructive sleep apnoea and postoperative outcome. Br J Anaesth, 2012;109, 6:897-906

2 Mokhlesi, B, Hovda, MD, Vekhter, B, et al. Sleep-disordered breathing and postoperative outcomes after elective surgery: analysis of the nationwide inpatient sample. Chest, 2013;144, 3:903-14 